\title{
Quantum Modeling of Enhanced Gate Control in a Nanoscale InAIAs/InGaAs DG-HEMT for millimeter-wave Applications
}

\author{
Neha Verma ${ }^{1}$, Mridula Gupta ${ }^{2}$, Enakshi Khular Sharma ${ }^{3}$, R.S. Gupta ${ }^{4}$, Jyotika \\ $\mathrm{Jogi}^{1}$ \\ ${ }^{\text {I }(M i c r o e l e c t r o n i c s}$ Research Laboratory, Department of Electronic Science, A.R.S.D College, University of \\ Delhi South Campus, New Delhi-110021, India) \\ ${ }_{2}^{2}$ (Semiconductor Device Research Laboratory, Department of Electronic Science, University of Delhi South \\ Campus, New Delhi-110021, India) \\ ${ }^{3}$ (Department of Electronic Science, University of Delhi South Campus, New Delhi-110021, India) \\ ${ }^{4}$ (Department of Electronics and Communication Engineering, Maharaja Agrasen Institute of Technology, New \\ Delhi-110086, India)
}

\begin{abstract}
This paper presents quantum model for nanoscale InAlAs/InGaAs double heterostructure double gate HEMT (DG-HEMT) accounting enhanced gate control for millimeter-wave applications. The eigenenergies obtained for different gate voltages has been used to calculate the corresponding quantum electron density in the channel and is employed to calculate various device characteristics. The obtained results have been compared with the simulated results obtained from quantum moments model and are found to be in good agreement.
\end{abstract}

Keywords: cut-off frequency, double-gate HEMT (DG-HEMT), electron density, quantum effects, separate gate.

\section{Introduction}

InAlAs/InGaAs HEMTs have become the most promising devices for high frequency microwave and millimeter-wave applications in military communication, remote imaging, real-time signal processing and MMICs [1-3]. They are also increasingly being used in high frequency products like mobile phones, satellite television, receivers and radar equipment. It is well established by now that the key to improve microwave performance lies in shrinking the gate length [4] and simultaneously maintaining a high aspect ratio to avoid short channel effects. But this scaling rule posed a physical limit on conventional HEMT structures and resulted in new device structure as a DG-HEMT, fabricated by transferred substrate technique [5-6], that not only minimized the short channel effects but also provided a better charge control through the second gate.

Considering that DG-HEMTs have extensive use in microwave applications and particularly with the continual shrinking of device dimensions to nanoscale, where quantum effects are dominant and cannot be overlooked, accurately modeling the various RF-parameters becomes imperative. In a double heterostructure DG-HEMT under consideration, there are two identical heterostructures forming two 2-DEGs (two dimensional electron gas) and resulting in symmetric double quantum wells wherein the perpendicular motion is constrained due to quantization. These two 2-DEGs formed in the nanoscale channel have been treated independently and the net device current was taken as twice that of a single channel, ignoring the interaction between the two quantum wells [7].

The authors in this paper treat the double triangular quantum wells (DTQW) in the channel as a system in order to evaluate the various device performance characteristics. The distribution of electrons in the channel controlled by the two gate potentials applied on either sides of the channel is calculated using the eigenenergies obtained by solving 1D time-independent Schrodinger equation for the potential profile in the channel. The various device characteristics comprising drain characteristics $\left(\mathrm{I}_{\mathrm{D}}-\mathrm{V}_{\mathrm{DS}}\right)$, transfer characteristics $\left(\mathrm{I}_{\mathrm{D}}-\mathrm{V}_{\mathrm{GS}}\right)$, output conductance $\left(\mathrm{g}_{\mathrm{d}}\right)$, transconductance $\left(\mathrm{g}_{\mathrm{m}}\right)$, gate-to- source capacitance $\left(\mathrm{C}_{\mathrm{GS}}\right)$ and finally the cut-off frequency $\left(\mathrm{f}_{\mathrm{T}}\right)$ for $100 \mathrm{~nm} \mathrm{In}{ }_{0.52} \mathrm{Al}_{0.48} \mathrm{As} / \mathrm{In}_{0.53} \mathrm{Ga}_{0.47} \mathrm{As} / \mathrm{In}_{0.52} \mathrm{Al}_{0.48} \mathrm{As}$ DG-HEMT have been evaluated to study the enhanced gate control. The analytical results have been compared with the simulated results obtained from quantum moments model available in SILVACO 3D ATLAS Device simulator [8] and are found to be in good agreement.

\section{Model}

The structure of nanoscale symmetric $\mathrm{In}_{0.52} \mathrm{Al}_{0.48} \mathrm{As} / \mathrm{In}_{0.53} \mathrm{Ga}_{0.47} \mathrm{As}$ DG-HEMT with various device dimensions and doping concentrations is shown in Fig. 1. The different parameters used in the present analysis are also given in TABLE I. As can be seen from Fig. 1, the structure has two symmetric heterostructures 
consisting of $\delta$-doped InAlAs and undoped InGaAs layers. The electrons transferred from InAlAs to InGaAs layers are expected to be confined in the double triangular quantum wells at the heterointerface. These electrons spatially separated from the ionized donors due to the presence of spacer layer, exhibit high mobility with high carrier concentrations in the channel attributing to remarkable device performance [3].

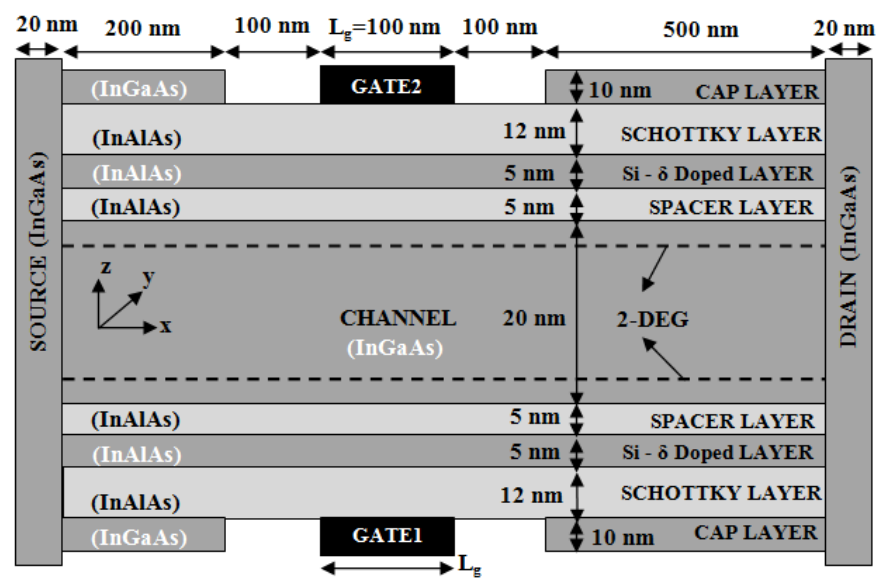

Fig. 1. Structure of InAlAs/InGaAs DG-HEMT.

Table I Eigenenergies With Different Electric Fields

\begin{tabular}{|c|c|c|c|}
\hline Parameter & Symbol & value & units \\
\hline Electron charge & $\mathrm{q}$ & $1.6^{*} 10^{-19}$ & $\mathrm{C}$ \\
\hline Electron mass & $\mathrm{m}_{\mathrm{o}}$ & $9.1^{*} 10^{-31}$ & $\mathrm{~kg}$ \\
\hline Effective mass of $\mathrm{In}_{0.53} \mathrm{Ga}_{0.47} \mathrm{As}$ & $\mathrm{m}^{*}$ & $0.033^{*} \mathrm{~m}_{\mathrm{o}}$ & $\mathrm{kg}$ \\
\hline Electron mobility & $\mu_{\mathrm{o}}$ & 0.83 & $\mathrm{~m} / \mathrm{V}-\mathrm{s}$ \\
\hline Saturation velocity & $v_{\mathrm{s}}$ & $2.63^{*} 10^{5}$ & $\mathrm{~m} / \mathrm{s}$ \\
\hline Boltzmann constant & $\mathrm{K}$ & $1.38^{*} 10^{-23}$ & $\mathrm{~J} / \mathrm{K}$ \\
\hline Reduced Planck constant & $\mathrm{h}$ & $1.05^{*} 10^{-34}$ & $\mathrm{~J}-\mathrm{s}$ \\
\hline Conduction band discontinuity & $\mathrm{V}_{0}$ & 0.5 & $\mathrm{eV}$ \\
\hline
\end{tabular}

The energy band-diagram for double heterostructures at equilibrium results in symmetric DTQW separated by a barrier as shown in Fig. 2(a). The potential profile for this system is also obtained using a 3-D ATLAS device simulator shown as solid lines in Fig. 2(b). The potential profile under an applied electric field resulting from the applied differential gate voltage (where Gate1 is maintained at $0 \mathrm{~V}$ and Gate 2 at different operating negative voltages, divided by the channel thickness) is shown in Fig. 3.

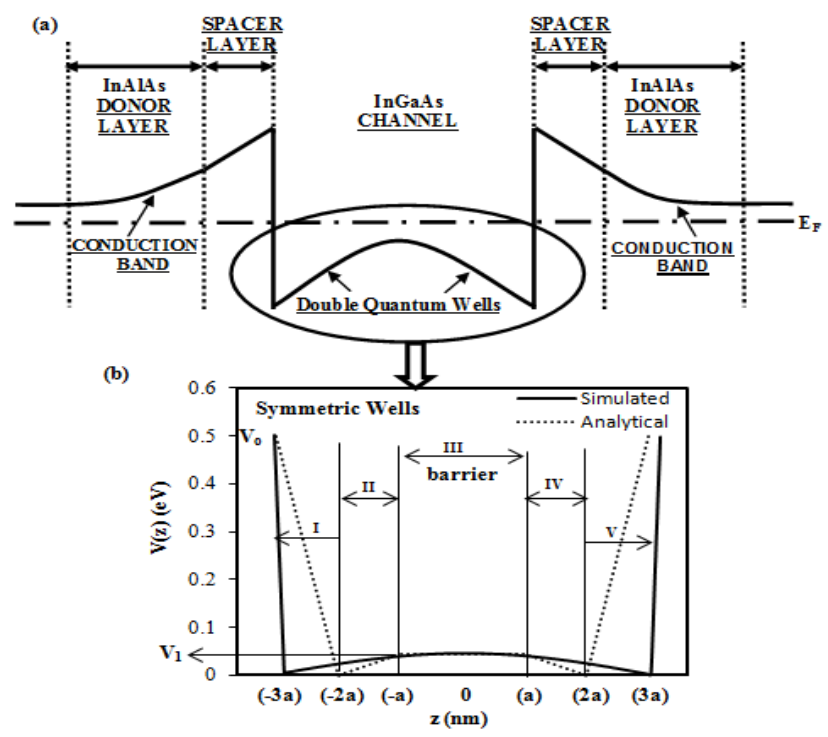

Fig. 2. Channel of DG-HEMT (a) Energy Band diagram for double heterostructures with symmetric double quantum wells. (b) Potential profile of a symmetric DTQW separated by a barrier formed in the channel at equilibrium. 


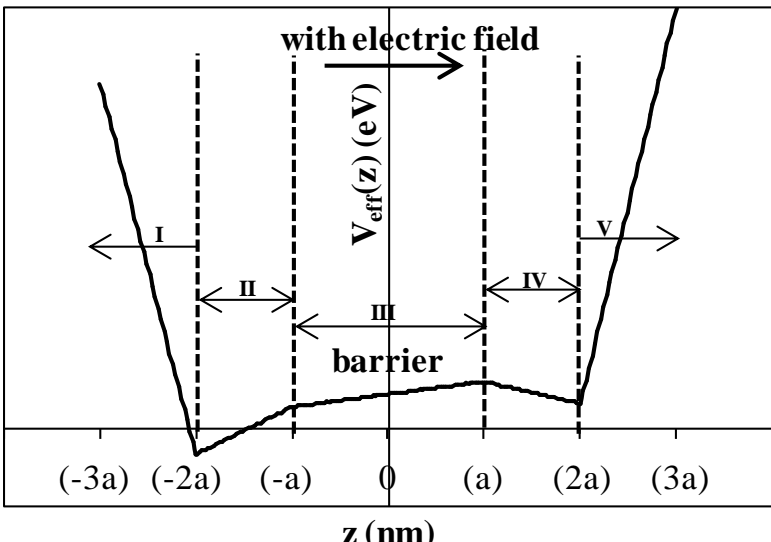

Fig. 3. Potential profile of DTQW separated by a barrier formed in the channel with applied electric field.

\subsection{Calculation of Eigenenergies}

The proposed analytical model uses an approximate potential profile $\mathrm{V}(\mathrm{z})$ for equilibrium (dotted lines in Fig. 2(b)) as:

$$
\mathrm{V}(\mathrm{z})= \begin{cases}\mathrm{V}_{0} \cdot\left(\frac{-2 \mathrm{a}-\mathrm{z}}{\mathrm{a}}\right), & \mathrm{z} \leq-2 \mathrm{a} \\ \mathrm{V}_{1} \cdot\left(\frac{\mathrm{z}+2 \mathrm{a}}{\mathrm{a}}\right), & -2 \mathrm{a} \leq \mathrm{z} \leq-\mathrm{a} \\ \mathrm{V}_{1}, & |\mathrm{z}| \leq \mathrm{a} \\ \mathrm{V}_{1} \cdot\left(\frac{2 \mathrm{a}-\mathrm{z}}{\mathrm{a}}\right), & \mathrm{a} \leq \mathrm{z} \leq 2 \mathrm{a} \\ \mathrm{V}_{0} \cdot\left(\frac{\mathrm{z}-2 \mathrm{a}}{\mathrm{a}}\right), & \mathrm{z} \geq 2 \mathrm{a}\end{cases}
$$

and effective potential $\mathrm{V}_{\text {eff }}(\mathrm{z})$ for applied electric field (in Fig. 3) as:

$$
V_{\text {eff }}(\mathrm{z})= \begin{cases}\mathrm{V}_{0} \cdot\left(\frac{-2 \mathrm{a}-\mathrm{z}}{\mathrm{a}}\right)+(\mathrm{eFz}), & \mathrm{z} \leq-2 \mathrm{a} \\ \mathrm{V}_{1} \cdot\left(\frac{\mathrm{z}+2 \mathrm{a}}{\mathrm{a}}\right)+(\mathrm{eFz}), & -2 \mathrm{a} \leq \mathrm{z} \leq-\mathrm{a} \\ \mathrm{V}_{1}+(\mathrm{eFz}), & |\mathrm{z}| \leq \mathrm{a} \\ \mathrm{V}_{1} \cdot\left(\frac{2 \mathrm{a}-\mathrm{z}}{\mathrm{a}}\right)+(\mathrm{eFz}), & \mathrm{a} \leq \mathrm{z} \leq 2 \mathrm{a} \\ \mathrm{V}_{0} \cdot\left(\frac{\mathrm{z}-2 \mathrm{a}}{\mathrm{a}}\right)+(\mathrm{eFz}), & \mathrm{z} \geq 2 \mathrm{a}\end{cases}
$$

Where, $\mathrm{V}_{0}$ represents the conduction band discontinuity, $\mathrm{V}_{1}$ is the height of the barrier between the two quantum wells (taken as $0.045 \mathrm{eV}$ as obtained in the simulated profile), the barrier thickness and the width of each well are taken as $2 \mathrm{a}$ where ' $\mathrm{a}$ ' is one sixth of the channel thickness. At equilibrium, as the potential profile is symmetric about the $\mathrm{z}=0$ axis, it is sufficient to consider the one dimensional time-independent Schrodinger equation for the region $0 \leq \mathrm{z} \leq 3 \mathrm{a}$. The eigenvalue equations obtained at equilibrium and at different applied electric fields are solved numerically to obtain the eigenenergies using Newton method [9-10]. The eigenenergies thus obtained are used to calculate the electron density in the channel. 


\subsection{Carrier Density in the Channel}

To calculate the carrier density for the quantum wells formed in the channel, the associated discrete energy levels must be known. These are obtained using the quantized energy levels calculated in the previous sub-section (2.1).

The total number of electrons in the channel is obtained using [11]:

$\mathrm{n}=\int_{0}^{\infty} \mathrm{D}(\mathrm{E}) \cdot \mathrm{f}(\mathrm{E}) \mathrm{dE}$

where $f(E)$ is the well-known Fermi-Dirac distribution and $D(E)$ is the effective density of states given by:

$$
\mathrm{D}(\mathrm{E})=\mathrm{D}_{1}(\mathrm{E}) \cdot \mathrm{D}_{2}(\mathrm{E})
$$

here $D_{1}(E)=\frac{m^{*}}{2 \pi \hbar^{2}}$ is the density of states for the continuum in the xy-plane and $D_{2}(E)$ is the density of states associated with the discrete set of states in the $\mathrm{z}$-direction given as [11]:

$$
\mathrm{D}_{2}(\mathrm{E})=\sum_{\mathrm{p}} \mathrm{H}\left(\mathrm{E}-\mathrm{E}_{\mathrm{p}}\left(\mathrm{V}_{\mathrm{GS}}, \mathrm{V}_{\mathrm{GS} 2}\right)\right)
$$

where $\mathrm{E}_{\mathrm{p}}\left(\mathrm{V}_{\mathrm{GS} 1}, \mathrm{~V}_{\mathrm{GS} 2}\right)$ is the lowest energy of the $\mathrm{p}^{\text {th }}$ electric sub-band which is controlled by the two gate potentials $\mathrm{V}_{\mathrm{GS} 1}$ and $\mathrm{V}_{\mathrm{GS} 2}$. Only the lowest two electric sub-bands are considered here as they are the main contributors for the electron concentration in the channel i.e. $\mathrm{p}=0$ and 1 for the ground $\left(\mathrm{E}_{0}\left(\mathrm{~V}_{\mathrm{GS} 1}, \mathrm{~V}_{\mathrm{GS} 2}\right)\right)$ and first excited state $\left(\mathrm{E}_{1}\left(\mathrm{~V}_{\mathrm{GS} 1}, \mathrm{~V}_{\mathrm{GS} 2}\right)\right)$ energy levels.

Therefore (5) becomes,

$$
\mathrm{D}_{2}(\mathrm{E})=\mathrm{H}\left(\mathrm{E}-\mathrm{E}_{0}\left(\mathrm{~V}_{\mathrm{GSl}}, \mathrm{V}_{\mathrm{GS} 2}\right)\right)+\mathrm{H}\left(\mathrm{E}-\mathrm{E}_{1}\left(\mathrm{~V}_{\mathrm{GSl}}, \mathrm{V}_{\mathrm{GS} 2}\right)\right)
$$

$\mathrm{H}\left(\mathrm{E}-\mathrm{E}_{\mathrm{p}}\left(\mathrm{V}_{\mathrm{GS} 1}, \mathrm{~V}_{\mathrm{GS} 2}\right)\right)$ is defined as:

$$
\begin{aligned}
\mathrm{H}\left(\mathrm{E}-\mathrm{E}_{\mathrm{p}}\left(\mathrm{V}_{\mathrm{GS}}, \mathrm{V}_{\mathrm{GS} 2}\right)\right) & =1 \text { for } \mathrm{E}=\mathrm{E}_{\mathrm{p}}\left(\mathrm{V}_{\mathrm{GSl}}, \mathrm{V}_{\mathrm{GS} 2}\right) \\
& =0 \text { for } \mathrm{E} \neq \mathrm{E}_{\mathrm{p}}\left(\mathrm{V}_{\mathrm{GSl}}, \mathrm{V}_{\mathrm{GS} 2}\right)
\end{aligned}
$$

Thus, the total number of electrons in the channel is obtained after substituting $f(E)$ and $D(E)$ in equation (3) as given by:

$$
\mathrm{n}=\left(\frac{\mathrm{m}^{*} \mathrm{kT}}{\pi \hbar^{2}}\right)_{\mathrm{p}} \ln \left[1+\exp \left\{\frac{\left(\mathrm{E}_{\mathrm{F}}-\mathrm{E}_{\mathrm{p}}\left(\mathrm{V}_{\mathrm{GS}}, \mathrm{V}_{\mathrm{GS} 2}\right)\right)}{\mathrm{kT}}\right\}\right]
$$

where $\mathrm{k}$ is the Boltzmann constant, $\mathrm{T}$ is the room temperature, $\mathrm{E}_{\mathrm{p}}\left(\mathrm{V}_{\mathrm{GS} 1}, \mathrm{~V}_{\mathrm{GS} 2}\right)$ is the $\mathrm{p}^{\text {th }}$ energy level and $\mathrm{E}_{\mathrm{F}}$ is the Fermi level [12].

The electron density [11] as a function of $\mathrm{z}$ can now be obtained by multiplying the number of electrons in $\mathrm{p}^{\text {th }}$ energy level by the probability $\left|\psi_{\mathrm{p}}(\mathrm{z})\right|^{2}$ :

$$
\mathrm{n}(\mathrm{z})=\sum_{\mathrm{p}} \mathrm{n}_{\mathrm{p}} \cdot\left|\psi_{\mathrm{p}}(\mathrm{z})\right|^{2}
$$

where $\mathrm{n}_{\mathrm{p}}$ is the number of electrons occupying the $\mathrm{p}^{\text {th }}$ energy level and $\psi_{\mathrm{p}}(\mathrm{z})$ is the normalized wavefunction corresponding to the $\mathrm{p}^{\text {th }}$ energy level $\mathrm{E}_{\mathrm{p}}\left(\mathrm{V}_{\mathrm{GS} 1}, \mathrm{~V}_{\mathrm{GS} 2}\right)$ [10]. Using (8) and the calculated eigenenergies, the electron density in the channel as a function of distance normal to the interface is obtained as: 
$\mathrm{n}(\mathrm{z})=\left(\frac{\mathrm{m}^{*} \mathrm{kT}}{\pi \hbar^{2}}\right)_{\mathrm{p}} \ln \left[1+\exp \left\{\frac{\left(\mathrm{E}_{\mathrm{f}}-\mathrm{E}_{\mathrm{p}}\left(\mathrm{V}_{\mathrm{GS}}, \mathrm{V}_{\mathrm{GS} 2}\right)\right)}{\mathrm{kT}}\right\}\right] \times\left|\psi_{\mathrm{p}}(\mathrm{z})\right|^{2}$

\subsection{Device Parameters}

The available analytical models for a double heterostructure DG-HEMT do not treat the channel and the two quantum wells as a combined system and instead assume that the net device current is twice that of a SG-HEMT [7]. The proposed analytical model in this paper evaluates the eigenenergy states of the double triangular quantum well separated by a barrier considering it as one system. The different device parameters are then calculated as follows:

\subsubsection{Drain to Source current}

The drain current $\left(I_{D}\right)$ flowing through the channel is given as:

$\mathrm{I}_{\mathrm{D}}\left(\mathrm{V}_{\mathrm{GS}}, \mathrm{V}_{\mathrm{GS} 2}\right)=\mathrm{w} \times\left(\mathrm{q} \cdot \mathrm{n}\left(\mathrm{V}_{\mathrm{GS}}, \mathrm{V}_{\mathrm{GS}}\right)\right) \times \mathrm{v}(\mathrm{x})$

where;

' $w$ ' is the device width taken as $100 \mathrm{um}$,

( $\left.\mathrm{q} \cdot \mathrm{n}\left(\mathrm{V}_{\mathrm{GS} 1}, \mathrm{~V}_{\mathrm{GS} 2}\right)\right)$ signifies the charge density with $\mathrm{q}$ as electron charge and $\mathrm{n}\left(\mathrm{V}_{\mathrm{GS} 1}, \mathrm{~V}_{\mathrm{GS} 2}\right)$ as the electron density which is a function of Gate $1\left(\mathrm{~V}_{\mathrm{GS} 1}\right)$ and Gate2 $\left(\mathrm{V}_{\mathrm{GS} 2}\right)$ obtained by integrating equation (10) over the entire channel depth from $z=-3 a$ to $z=3 a$ (and dividing by the depth of the channel $(20 \mathrm{~nm})$.

The velocity-field relationship $v(\mathrm{x})$ used in the present analysis is given by [13]:

$v(x)=\frac{\mu_{0} \cdot E_{c}(x)}{1+\frac{\mu_{0}}{v_{s}} \cdot E_{c}(x)}$

where $\mu_{0}$ is the constant electron mobility, $v_{\mathrm{s}}$ is the saturation velocity and the field $\mathrm{E}_{\mathrm{c}}(\mathrm{x})$ is given as:

$E_{c}(x)=\frac{d V(x)}{d x}$

Making the above substitutions in (11) and integrating from the source $(\mathrm{x}=0)$ to drain $\left(\mathrm{x}=\mathrm{L}_{\mathrm{g}}\right)$, the drainto-source current for the double heterostructure DG-HEMT is obtained as:

$$
\mathrm{I}_{\mathrm{D}}\left(\mathrm{V}_{\mathrm{GS1}}, \mathrm{V}_{\mathrm{GS} 2}\right)=\frac{\mathrm{q} \cdot \mathrm{w} \cdot \mu_{0} \cdot \mathrm{n}\left(\mathrm{V}_{\mathrm{GS}}, \mathrm{V}_{\mathrm{GS} 2}\right) \mathrm{V}_{\mathrm{DS}}}{\mathrm{L}_{\mathrm{g}}\left[1+\left(\frac{\mu_{0} \mathrm{~V}_{\mathrm{DS}}}{\mathrm{L}_{\mathrm{g}} v_{\mathrm{s}}}\right)\right]}
$$

\subsubsection{Transconductance and Output Conductance}

Transconductance $\left(g_{m}\right)$ and output conductance $\left(g_{d}\right)$ both govern the intrinsic gain of the device $\left(\mathrm{g}_{\mathrm{m}} / \mathrm{g}_{\mathrm{d}}\right)$. Transconductance is considered as an essential indicator for evaluating the device performance for highfrequency applications. It is a measure of the sensitivity of drain current to change in gate-to-source voltage. The two separate gates in a double heterostructure DG-HEMT control the drain current. Thus, the enhanced gate controls need to be studied by evaluating the sensitivity of the drain current to changes in either gate voltage. given as:

For two separate gate controls $\left(\mathrm{V}_{\mathrm{GS} 1}\right.$ and $\left.\mathrm{V}_{\mathrm{GS} 2}\right)$ the transconductance corresponding to either gate $\mathrm{g}_{\mathrm{mi}}$ is

$$
g_{\mathrm{mi}}=\left.\frac{\mathrm{dI}_{\mathrm{D}}\left(\mathrm{V}_{\mathrm{GSl}}, \mathrm{V}_{\mathrm{GS} 2}\right)}{\mathrm{dV}_{\mathrm{GSi}}}\right|_{\begin{array}{l}
\mathrm{V}_{\mathrm{DS}=\text { const }} \\
\mathrm{V}_{\mathrm{GSj}=\text { const }} \\
\text { where } \mathrm{i} \neq \mathrm{j}
\end{array}}
$$


Similarly output conductance that plays an important role in determining the maximum voltage gain attainable from the device is defined as the incremental change in the drain-current with the drain-to-source voltage $\left(\mathrm{V}_{\mathrm{DS}}\right)$ at a fixed gate-to-source voltage. For two separate gate controls $\left(\mathrm{V}_{\mathrm{GS} 1}\right.$ and $\left.\mathrm{V}_{\mathrm{GS} 2}\right) \mathrm{g}_{\mathrm{d}}$ is given as:

$$
\mathrm{g}_{\mathrm{d}}=\left.\frac{\mathrm{dI}_{\mathrm{D}}\left(\mathrm{V}_{\mathrm{GS} 1}, \mathrm{~V}_{\mathrm{GS} 2}\right)}{\mathrm{dV}_{\mathrm{DS}}}\right|_{\mathrm{V}_{\mathrm{GS} 1}, \mathrm{~V}_{\mathrm{GS} 2}=\text { const }}
$$

\subsubsection{Gate-to-Source Capacitance and Cut-off frequency}

Another important parameter that affects the device performance is Gate-to-source capacitance which is defined as the change in total charge $\left(\mathrm{q} \cdot \mathrm{n}\left(\mathrm{V}_{\mathrm{GS} 1}, \mathrm{~V}_{\mathrm{GS}}\right)\right)$ with the change in gate-to-source voltage. The two gates control the gate to source capacitance separately. Also, the cut-off frequency $\left(\mathrm{f}_{\mathrm{T}}\right)$ that determines the ultimate speed of the device and is considered as an important figure of merit of the device performance controlled by the two gates separately and is given by:

$$
f_{T i}\left(V_{G S 1}, V_{G S 2}\right)=\frac{g_{m i}\left(V_{G S 1}, V_{G S 2}\right)}{2 \cdot \pi \cdot C_{G S}\left(V_{G S 1}, V_{G S 2}\right)}
$$

\section{Results and Discussion}

The eigenenergies obtained for the ground and first excited energy state, that correspond to the symmetric and antisymmetric states for equilibrium and various applied gate voltages, are given in TABLE II and shown in Fig. 4(a). It can be observed that the eigenenergy corresponding to ground level decreases with an increase in the negative bias on Gate 2 while the eigenenergy corresponding to first excited energy state increases. However, the increase in $E_{1}$ is much lower than the corresponding decrease in $E_{0}$ energy level which shows a greater effect of gate voltage on $\mathrm{E}_{0}$. The difference between $\mathrm{E}_{0}$ and $\mathrm{E}_{1}$ is seen to be controlled by both the gates independently. When Gate1 is held at zero bias with respect to the source, the Gate2 is further controlling the eigenenergies which would lead to a consequent variation in carrier density.

Table Ii

Eigenenergies With Different Electric Fields

\begin{tabular}{|c|c|c|c|}
\hline S.No. & $\begin{array}{c}\text { Voltage applied at Gate2 }\left(\mathrm{V}_{\mathrm{GS} 2}\right)(\mathrm{V}) \\
\left.\text { (for } \mathrm{V}_{\mathrm{GS} 1}=0 \mathrm{~V}\right)\end{array}$ & $\mathrm{E}_{0}(\mathrm{eV})$ & $\mathrm{E}_{1}(\mathrm{eV})$ \\
\hline 1. & $\mathrm{~V}_{\mathrm{GS} 2}=0$ & 0.0689 & 0.1504 \\
\hline 2. & $\mathrm{~V}_{\mathrm{GS} 2}=-0.04$ & 0.0683 & 0.1506 \\
\hline 3. & $\mathrm{~V}_{\mathrm{GS} 2}=-0.1$ & 0.0649 & 0.1518 \\
\hline 4. & $\mathrm{~V}_{\mathrm{GS} 2}=-0.15$ & 0.0602 & 0.1532 \\
\hline 5. & $\mathrm{~V}_{\mathrm{GS} 2}=-0.2$ & 0.0539 & 0.1548 \\
\hline 6. & $\mathrm{~V}_{\mathrm{GS} 2}=-0.25$ & 0.0465 & 0.1563 \\
\hline 7. & $\mathrm{~V}_{\mathrm{GS} 2}=-0.3$ & 0.0380 & 0.1575 \\
\hline
\end{tabular}

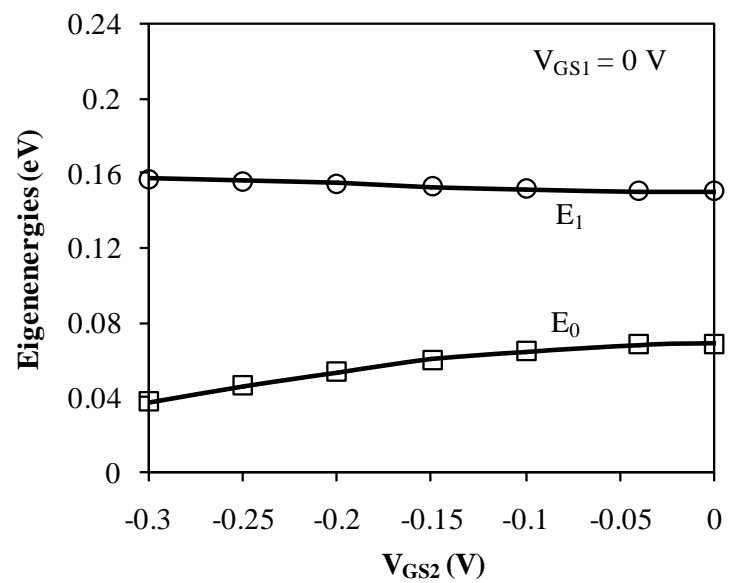

Fig. 4(a). Behavior of eigenenergies in the channel at various separate gate voltages. 
The electron density $\left(\mathrm{n}\left(\mathrm{V}_{\mathrm{GS} 1}, \mathrm{~V}_{\mathrm{GS} 2}\right)\right)$ in the channel, obtained using the eigenenergies, a function of both the gate voltages is shown in Fig. 4(b). The electron density is found to vary with and thus controlled by the two gate voltages as seen. Here, it can be observed from the figure that a larger contribution to the electron density in the channel is from the electrons occupying the lower energy state $\mathrm{E}_{0}$, which in turn varies with the two gate voltages whereas the contribution due to first excited state does not show any significant change with the gate potential. So it can be inferred that the enhanced gate control on the carrier concentration in the channel is mainly due to the gate potentials controlling the ground state of the DTQW formed at the two interfaces and

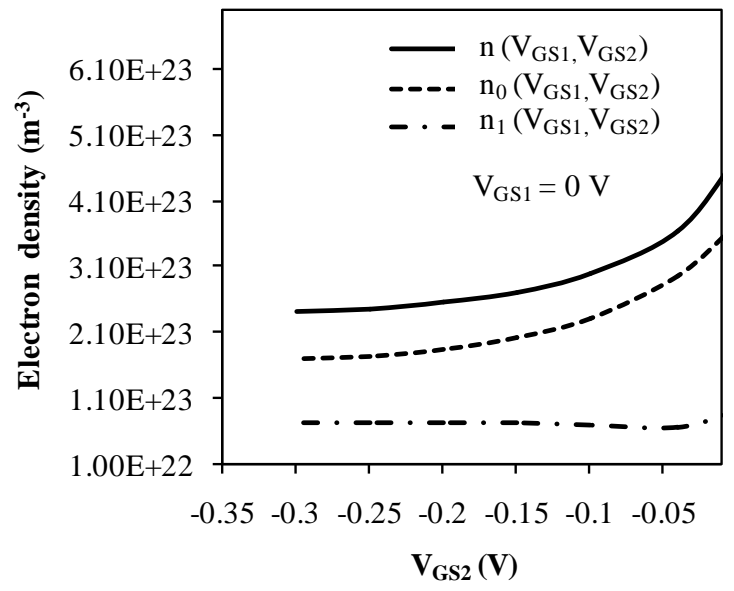

Fig. 4(b). Variation of electron density in the channel, $\mathrm{n}\left(\mathrm{V}_{\mathrm{GS} 1}, \mathrm{~V}_{\mathrm{GS} 2}\right)$, at various separate gate voltages, $\mathrm{n}_{0}\left(\mathrm{~V}_{\mathrm{GS} 1}, \mathrm{~V}_{\mathrm{GS} 2}\right)$ and $\mathrm{n}_{1}\left(\mathrm{~V}_{\mathrm{GS} 1}, \mathrm{~V}_{\mathrm{GS} 2}\right)$ represent the electron density due to $\mathrm{E}_{0}$ and $\mathrm{E}_{1}$ respectively.

Separated by the bulk of the channel acting as the barrier. As the gate potential decreases, there is a lowering in $\mathrm{E}_{0}$ of the combined system which suggests a tunneling from one well to the other. This is observed in Fig. 5 where the electron density profile at equilibrium and at separate gate voltages i.e. $\mathrm{V}_{\mathrm{GS} 1}=0 \mathrm{~V}$ and $\mathrm{V}_{\mathrm{GS} 2}=-$ $0.2 \mathrm{~V}$ are given. A significant shift in the peak is observed, showing a movement of electrons away from the well closer to the gate at lower potential to the well closer to the gate at higher bias voltage. Thus, a better control of the electron distribution in the channel can be achieved by two gates separately. The analytical results have been compared with the simulated results obtained from Quantum moments model available in 3D ATLAS Device simulator show a good match, thus, validating the proposed model.

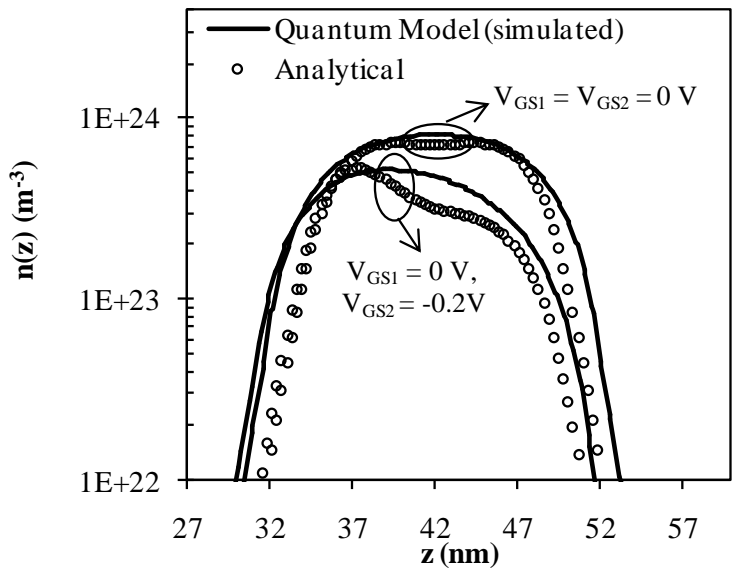

Fig. 5. Comparison of Electron density in the channel at equilibrium and applied separate gate voltages.

Fig. 6 presents the drain current $\left(\mathrm{I}_{\mathrm{D}}\right)$ versus drain voltage $\left(\mathrm{V}_{\mathrm{DS}}\right)$ characteristics for different Gate2 bias $\left(\mathrm{V}_{\mathrm{GS} 2}\right)$ and with constant Gate1 bias $\left(\mathrm{V}_{\mathrm{GS} 1}\right)$. Both the gate voltages modulate the current in the channel which can be seen from the figure. As the negative potential on the Gate 2 increases from $0 \mathrm{~V}$ to $-0.2 \mathrm{~V}$ with constant $\mathrm{V}_{\mathrm{GS} 1}=0 \mathrm{~V}$, there is a decrease in the drain current as the carriers deplete accordingly. 


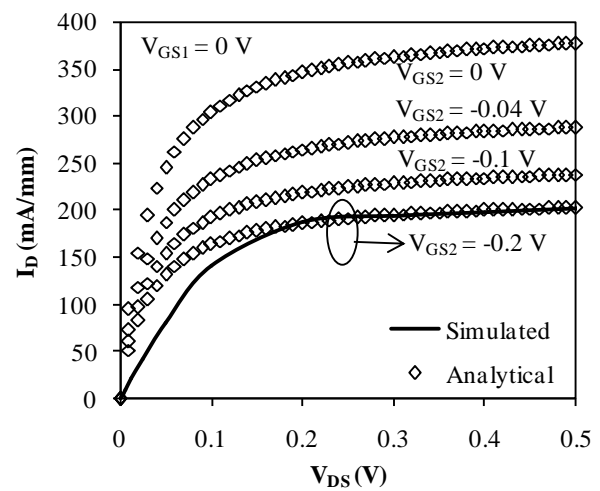

Fig. 6. $\mathrm{I}_{\mathrm{D}}-\mathrm{V}_{\mathrm{DS}}$ characteristics for $\mathrm{V}_{\mathrm{GS} 1}=0 \mathrm{~V}$ and different $\mathrm{V}_{\mathrm{GS} 2}$.

Fig. 7 demonstrates the comparison of $I_{D}-V_{D S}$ characteristics for $100 \mathrm{~nm}$ and $50 \mathrm{~nm}$ DG-HEMT for different Gate2 voltages $\left(\mathrm{V}_{\mathrm{GS} 2}\right)$ and constant $\mathrm{V}_{\mathrm{GS} 1}=0 \mathrm{~V}$. The authors used the same structure that had been fabricated for $100 \mathrm{~nm}$ and only scaled down the gate length to $50 \mathrm{~nm}$ [14]. Effect of gate controls on drain current for different gate lengths, with aspect ratio of 4.5 and 2.27, has been shown here. As observed there is a faster increase in the drain current for shorter gate length, thus proposing a faster device with enhanced separate gate controls. The figure depicts a slight increase in the saturation current density when the gate-length is reduced from $100 \mathrm{~nm}$ to $50 \mathrm{~nm}$ which shows that the gate length of DG-HEMT can be scaled to shorter gate lengths to improve the performance maintaining an adequate device aspect ratio also.

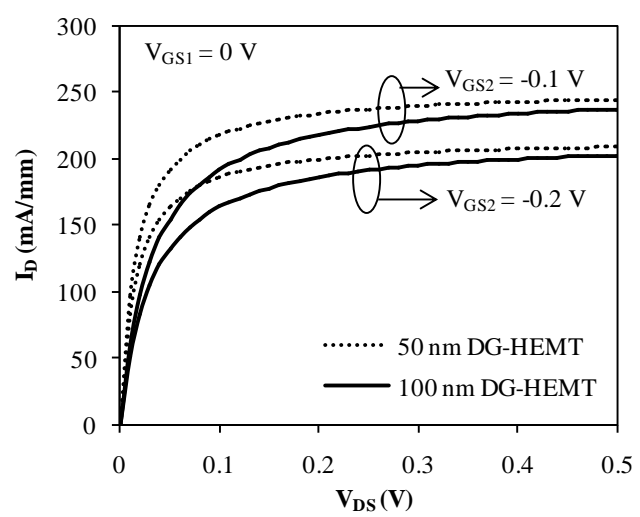

Fig. 7. Comparison of $\mathrm{I}_{\mathrm{D}}-\mathrm{V}_{\mathrm{DS}}$ characteristics for $100 \mathrm{~nm}$ and $50 \mathrm{~nm}$ DG-HEMT.

Fig. 8 illustrates the transfer characteristics $\left(\mathrm{I}_{\mathrm{D}}-\mathrm{V}_{\mathrm{GS} 2}\right)$ at constant $\mathrm{V}_{\mathrm{DS}}=0.1 \mathrm{~V}$ and $\mathrm{V}_{\mathrm{GS} 1}=0 \mathrm{~V}$. It shows the drain current dependence on gate to source voltage for $100 \mathrm{~nm}$ DGHEMT at constant $\mathrm{V}_{\mathrm{DS}}$. This result suggests that the drain current can be controlled by one of the gate voltages while the other is held constant. This kind of a configuration can have useful mixer applications in millimeter wave communication systems.

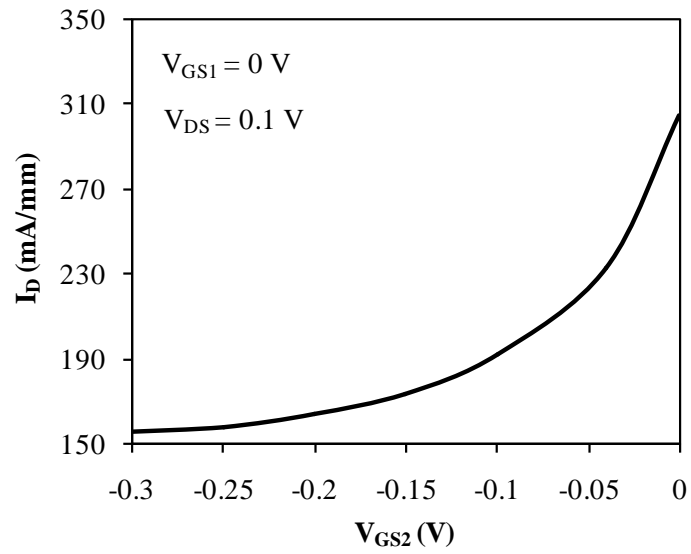

Fig. 8. $\mathrm{I}_{\mathrm{D}}-\mathrm{V}_{\mathrm{GS} 2}$ characteristics for $100 \mathrm{~nm}$ DGHEMT for $\mathrm{V}_{\mathrm{DS}}=0.1 \mathrm{~V}$. 
Fig. 9 presents an output (drain) conductance $\left(\mathrm{g}_{\mathrm{d}}\right)$ versus drain-to-source voltage at constant $\mathrm{V}_{\mathrm{GS} 1}=0 \mathrm{~V}$ and $\mathrm{V}_{\mathrm{GS} 2}=-0.1 \mathrm{~V}$ and $-0.2 \mathrm{~V}$. The output conductance plays an important role in determining the maximum voltage gain attainable from the device. The output conductance is observed to decrease with decrease in Gate 2 voltage for a constant Gate1 voltage. This happens due to reduction in carrier concentration in the channel with a reduction in Gate 2 voltage which in turn gives a lower increment in drain current with $\mathrm{V}_{\mathrm{DS}}$.

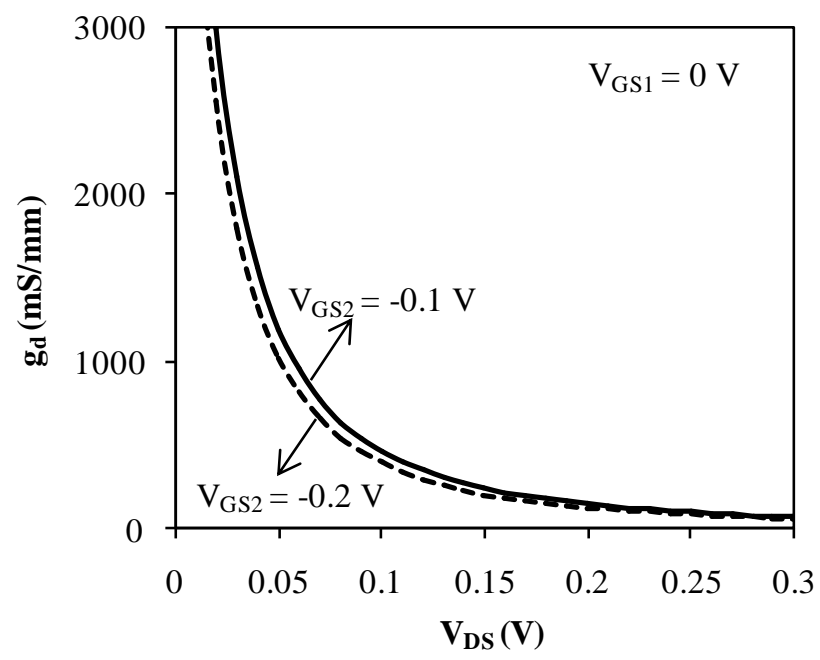

Fig. 9. $\mathrm{g}_{\mathrm{d}}$ versus $\mathrm{V}_{\mathrm{DS}}$ for $\mathrm{V}_{\mathrm{GS} 2}=-0.1$ and $-0.2 \mathrm{~V}$.

Fig. 10 presents the transconductance $\left(\mathrm{g}_{\mathrm{m}}\right)$ and gate-to-source capacitance $\left(\mathrm{C}_{\mathrm{GS}}\right)$ (inset) versus gate-tosource voltage $\mathrm{V}_{\mathrm{GS} 2}$ showing the control of the gate on the channel current. An increase in both $\mathrm{g}_{\mathrm{m}}$ and $\mathrm{C}_{\mathrm{GS}}$ with Gate2 voltage while Gate1 is held constant provides greater gain and superior high-frequency performance. It exhibits the ratio of current change at the output to the voltage change at the input and its value is associated with the speed of the device that acts as an indicator for high frequency applications. The figure in inset shows $\mathrm{C}_{\mathrm{GS}}$, modeling the change in the total charge with Gate2 voltage. This suggests an application where the amplification of the signal at one of the gates can be controlled by the bias at the other gate in a separate gate

\section{DG-HEMT.}

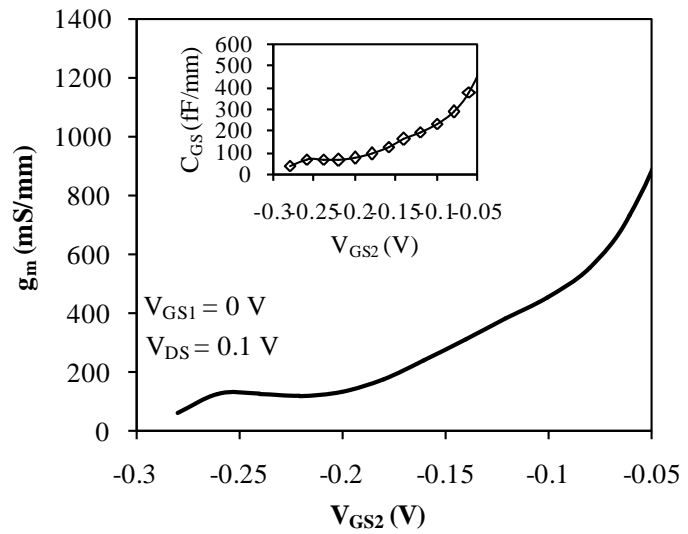

Fig. 10. $\mathrm{g}_{\mathrm{m}}$ and $\mathrm{C}_{\mathrm{GS}}$ versus $\mathrm{V}_{\mathrm{GS} 2}$ for $\mathrm{V}_{\mathrm{DS}}=0.1 \mathrm{~V}$.

Finally, Fig. 11 presents the variation of significant characterization parameter of the device i.e. the cut-off frequency $\left(\mathrm{f}_{\mathrm{T}}\right)$ with $\mathrm{V}_{\mathrm{GS} 2}$ for $\mathrm{V}_{\mathrm{DS}}=0.1 \mathrm{~V}$ and $\mathrm{V}_{\mathrm{GS} 1}=0 \mathrm{~V}$ using the proposed analytical model and shown in Fig. 11. A maximum cut off frequency, $\mathrm{f}_{\mathrm{T}}$, of $317 \mathrm{GHz}$ is obtained for the device using the proposed analytical model which is ideal for the high frequency microwave and millimeter-wave applications. 


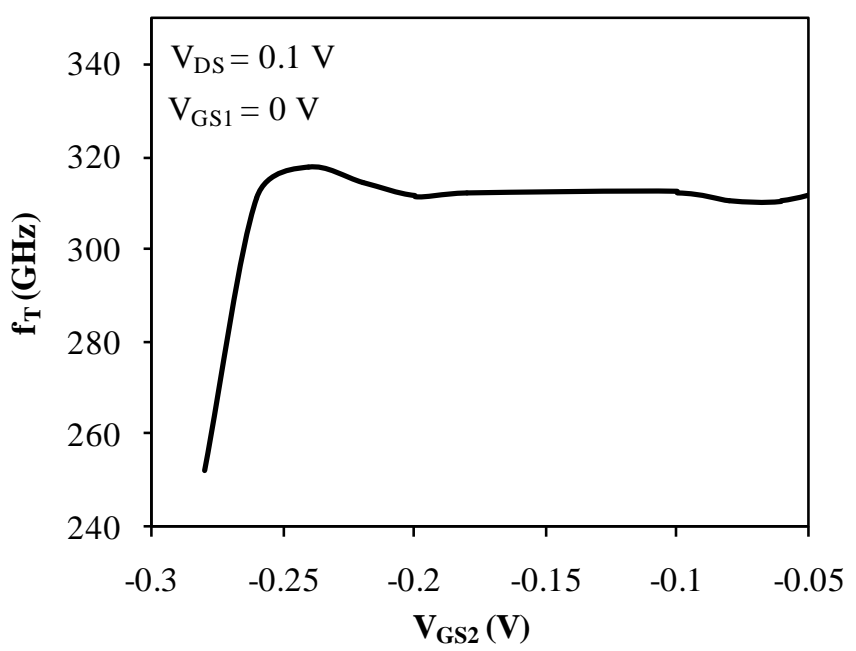

Fig. 11. $\mathrm{f}_{\mathrm{T}}$ versus $\mathrm{V}_{\mathrm{GS} 2}$ for $\mathrm{V}_{\mathrm{DS}}=0.1 \mathrm{~V}$.

\section{Conclusion}

This paper presents an analytical model to predict and study the enhanced gate control on the important device parameters by the two separate gates in $100 \mathrm{~nm}$ symmetric double heterostructure InAlAs/InGaAs DGHEMT for millimeter-wave applications. The enhanced control of gate voltages on the eigenenergies i.e. the ground state energy level $\left(\mathrm{E}_{0}\right)$ and first excited state energy level $\left(\mathrm{E}_{1}\right)$ consequently control the electron density in the channel. A shift in peak of the electron density observed shows the control of the two separate gate voltages applied which then effectively control the drain current. The control of the drain current by one of the gate voltages while keeping the other at constant can be advantageous for various mixer applications, thus, predicting the application of the device for high frequency system applications.

\section{Acknowledgements}

The authors acknowledge University Grants Commission for providing financial support for this work.

\section{References}

[1] K. Shinohara, Y. Yamashita, A. Endoh, K. Hikosaka, T. Matsui, T. Mimura, and S. Hiyamizu, "Ultrahigh-Speed Pseudomorphic InGaAs/InAlAs HEMTs With 400-GHz Cutoff Frequency,” IEEE Electron Device Lett., vol. 22, 2001, pp. 507-509.

[2] C. Pobanz, M. Matloubian, V. Radisic, G. Raghavan, M. Case, M. Micovic, M. Hu, C. Nguyen, S. Weinreb, and L. Samoska, "High performance MMICs with submillimeter wave InP-based HEMTs," in Proc. IEEE IPRM, 2000, Williamsburg, VA, pp. 6770.

[3] C. Y. Chang, and F. Kai, GaAs high-speed devices (U.S. A, John Wiley \& Sons, Inc., 1994).

[4] Y. Yamashita, A. Endoh, K. Shinohara, K. Hikosaka, T. Matsui, S. Hiyamizu and T. Mimura, "Pseudomorphic In ${ }_{0.52} \mathrm{Al}_{0.48} \mathrm{As}_{-}$ $\mathrm{In}_{0.53} \mathrm{Ga}_{0.47}$ As HEMTs with an ultrahigh $\mathrm{f}_{\mathrm{T}}$ of $562 \mathrm{GHz}$," IEEE Electron Device Lett., vol. 23, 2002, pp. $573-575$.

[5] N. Wichmann, I. Duszynski, S. Bollaert, J. Mateos, X. Wallart, and A. Cappy, "100 nm InAlAs/InGaAs double-gate HEMT using transferred substrate," in IEDM Tech. Dig., 2004, pp. 1023-1026.

[6] N. Wichmann, I. Duszynski, X. Wallart, S. Bollaert, and A. Cappy, "InAlAs-InGaAs Double-Gate HEMTs on Transferred Substrate," IEEE Electron Device Lett., vol. 26, 2004, pp. 354-356.

[7] M. Bhattacharya, J. Jogi, R. S. Gupta, and M. Gupta, "Impact of Doping concentration and Donor-layer thickness on the dc characterization of symmetric Double-gate and Single-gate InAlAs/InGaAs/InP HEMT for nanometer gate dimension-A comparison," in IEEE TENCON, 2010, Fukuoka, Japan, pp. 134- 139.

[8] ATLAS User's Manual (version: 5.16.3.R), Silvaco International; 2010

[9] N. Verma, E. K. Sharma, and J. Jogi, "Eigenenergies of a Nanoscale Symmetric Double Triangular Quantum Well in Double Gate InAlAs/InGaAs HEMT," in EEIC 2013, Hong Kong, China, pp. 14-16.

[10] N. Verma, E.K. Sharma and J. Jogi, "Modeling Quantum Effects In The Channel Of A Nanoscale Symmetric Double Gate InAlAs/InGaAs Double Heterosteructure HEMT," IOSR Journal of Electrical and Electronics Engineering, vol. 9, no. 1(4), 2014, pp. 20-28.

[11] A. P. Gnädinger, and H.E. Talley, "Quantum mechanical calculation of the carrier distribution and the thickness of the inversion layer of a MOS Field-Effect Transistor," Solid-State Electronics, vol. 13(9), 1970, pp. 1301-1309.

[12] N. Dasgupta, and A. Dasgupta, "An analytical expression for sheet carrier concentration versus gate voltage for HEMT modeling," Solid State Electronics, vol. 36(2), 1993, pp. 201-203.

[13] J. Jogi, S. Sen, M. Gupta, and R.S. Gupta, "Carrier-concentration-dependent low-field-mobility model for InAlAs/InGaAs/InP lattice-matched HEMT for microwave application,” Microwave Opt Tech Lett., vol. 29, 2001, pp. 66-70.

[14] B. G. Vasallo, N. Wichmann, S. Bollaert, Y. Roelens, A. Cappy, T. Gonzalez, D. Pardo, and J. Mateos, "Comparison Between the Dynamic Performance of Double- and Single-Gate AlInAs/InGaAs HEMT," IEEE Trans Electron Dev., vol. 54, 2007, pp. 28152822 . 